\title{
Transformational Leadership Enhances The Action Of Augmentative And Alternative Communication In Stroke Patients Aphasia Motor
}

\section{Transformasional Leadership Meningkatkan Tindakan Augmentative And Alternative Communication pada Pasien Stroke Afasia Motorik}

Dwi Febryanto*, Hasib Ardani

\begin{abstract}
About $21 \%-35 \%$ of patients with acute stroke experience aphasia or motor impairment language interpretation. Impact because of the lack of action independence of the nurse in improving Augmentative Alternative Communication (AAC) is not the fulfillment of the needs of the patient. AAC is media in the form of electronic devices, alphabet boards, drawing boards that contain the basic needs which may be designated by the patient that helps in communicating.

The research method is a literature research, focused on the search of some previous research. The results of the research show that the role of transformational leadership increase the AAC in stroke patients aphasia motor through insiparasional motivation where the leader becomes an example to be emulated by subordinates, providing a strong motivation for change with guidance and training, individualizad consideration that is hear input to want to change apply the AAC, Idealized influence where the leader as a mentor who has charisma makes followers want to practice the AAC, and intellectual stimulation is to encourage the subordinates to see problems in aphasia motor can be minimized with the AAC. Thus it can be concluded that the Style of transformational leadership may benefit the nurse endeavor in AAC therapy.
\end{abstract}

Keywords: Transformational Leadership, Augmentative Alternative Communication (AAC), stroke, aphasia motor.

Afiliasi Penulis

Magister Keperawatan Universitas Diponegoro, Semarang

Korespondensi kepada

D. Febryanto

dwifebryanto37@gmail.com 


\section{Intisari}

Sekitar 21\%-35\% pasien stroke akut mengalami afasia motorik atau gangguan interpretasi bahasa. Dampak karena kurangnya tindakan kemandirian perawat dalam meningkatkan Augmentative Alternative Comunication (AAC) adalah tidak terpenuhinya kebutuhan pasien. AAC adalah media berupa perangkat elektronik, papan alfabet, papan gambar yang berisi kebutuhan dasar yang dapat ditunjuk oleh pasien yang berfungsi membantu dalam berkomunikasi.

Metode penelitian adalah literature research, menitikberatkan pada pencarian beberapa penelitian sebelumnya. Hasil penelitian menunjukkan bahwa peran dari kepemimpinan transformasional meningkatkan AAC pada pasien stroke afasia motorik melalui insiparasional motivation dimana pemimpin menjadi contoh yang perlu ditiru oleh bawahan, memberi motivasi yang kuat untuk berubah dengan bimbingan dan pelatihan $A A C$, individualizad consideration yaitu mendengar masukan masukan untuk mau berubah menerapkan AAC, Idealized influence dimana pemimpin sebagai mentor yang memiliki kharisma membuat pengikutnya mau berlatih AAC, dan intellectual stimulation yaitu mendorong bawahan agar melihat persoalan afasia motorik dapat diminimalisir dengan AAC. Dengan demikian dapat ditarik kesimpulan bahwa Gaya kepemimpinan transformasional dapat digunakan untuk upaya perawat melatih terapi AAC.

Kata kunci: Transformasional Leadership, Augmentatif Alternative Comunication (AAC), stroke, afasia motorik.

\section{Pendahuluan}

Kasus stroke baru terjadi pada 100 sampai 300 orang per 100000 penduduk pertahun. Stroke pembunuh nomer 3 setelah penyakit jantung dan kanker, namun merupakan penyebab kecacatan nomer satu (Pinzon, 2016).

Stroke adalah gangguan aliran pembuluh darah otak yang menimbulkan gangguan neurologis berupa kecacatan, kelumpuhan anggota gerak, proses berfikir dan gangguan bicara atau afasia (Muttaqin dalam Dwi, dkk 2014).

Menurut Price \& Wilson dalam Amila, dkk (2015) sekitar 21-35\% pasien stroke akut dapat mengalami afasia yang merupakan gangguan interpretasi bahasa yang disebabkan oleh cedera otak atau proses patologik stroke di hemisfer kiri otak pada area Broca, area Wernicke dan jalur yang menghubungkan antara keduanya.

Berdasarkan hasil penelitian Bahr (2008) menunjukkan bahwa pasien stroke yang mengalami afasia mengalami kesulitan untuk berkomunikasi, sehingga memerlukan intervensi kemandirian perawatan yang tepat.

Hasil sistematik review yang dilakukan Poslawsky dalam Amila, dkk (2015) menjelaskan tentang tindakan mandiri perawat dalam terapi Augmentatif and Alternative Comunication (AAC) pada pasien stroke yang mengalami afasia secara intensif yang dimulai pada fase akut menunjukkan hasil rehabilitasi yang terbaik terhadap fungsi berbahasa sehingga sangat penting untuk tercapainya proses rehabilitasi yang optimal.

Hal yang harus diperhatikan dalam meningkatkan tindakan mandiri perawat dalam melakukan AAC adalah pengetahuan perawat, motivasi dan ketrampilan serta tersedianya alat atau media AAC untuk melatih terapi bicara pasien stroke afasia motorik agar dapat berkomunikasi (Amila et al., 2015)

Media Augmentative and Alternative Communication (AAC) berupa perangkat elektronik, papan alfabet, papan gambar/ flash card yang berisi gambar kebutuhan dasar, stimulus visual, alat tulis, kata-kata yang sederhana, bahan yang berisi tulisan atau gambar yang dapat ditunjuk oleh pasien yang berfungsi untuk membantu pasien dalam berkomunikasi (Beukelman, Hux, Dietz, McKelvey, \& Weissling, 2015).

Dampak yang ditimbulkan karena kurangnya tindakan kemandirian perawat dalam meningkatkan $A A C$ adalah tidak terpenuhinya 
kebutuhan pasien dan bisa terjadi salah persepsi antara perawat dan pasien akibat komunikasi yang tidak maksimal selain itu dapat mempengaruhi kesejahtraan pasien, kemandirian, partisipasi sosial, dan kualitas hidup akibat keterbatasan komunikasi.

Kondisi ini dapat terjadi karena pasien tidak mampu mengungkapkan apa yang mereka inginkan, tidak mampu menjawab pertanyaan atau berpartisipasi dalam percakapan, sehingga pasien menjadi frustasi, marah, kehilangan harga diri dan emosi pasien menjadi labil. Keadaan ini akhirnya menyebabkan pasien menjadi depresi (Mulyatsih, 2010 dalam Amila et al., 2015). Melihat hal tersebut maka dibutuhkan perubahan oleh seorang leader.

Menurut Crainer di kutip dari Yudiaatmaja (2013) leadership merupakan kemampuan memperoleh kesepakatan upaya mencapai tujuan tertentu. Seorang leader perlu menerapkan gaya gaya kepemimpinan yang berpengaruh pada kemandirian bawahan untuk mencapai hasil yang memuaskan.

Gaya kepemimpinan transformasional merupakan gaya pemimpin yang menginspirasi para pengikutnya untuk mengesampingkan kepentingan pribadi mereka dan memiliki kemampuan mempengaruhi yang luar biasa (Robbins dan Judge, 2008:90 dalam Pradhanawati, 2012)

Menurut Bass dan Avolio dalam (Pradhanawati, 2012) kepemimpinan transformasional yang otentik mengandung empat komponen yakni: (1) Idealized Influence (2) Inspirational Motivation (3) Intellectual Stimulation (4) Individualized Consideration.

Gaya kepemimpinan transformasional dibutuhkan untuk mengurangi dampak kurangnya komunikasi pasien dan perawat sebagai akibat afasia motorik stroke melalui tindakan meningkatkan Augmentative and Alternative Comunication (AAC).

Tujuan Literature review ini untuk meningkatkan tindakan Augmentative and Alternative Comunication $(A A C)$ pada pasien stroke afasia motorik melalui transformasional leadership.

\section{Metode}

Metode penelitian yang digunakan adalah literature research, dimana penelitian ini menitikberatkan pada pencarian beberapa penelitian sebelumnya. Hasil tersebut akan memetakan mengenai bagaimana peran dari kepemimpinan transformasional dalam konteks meningkatkan tindakan Augmentative and Alternative Comunication ( $A A C$ ) pada pasien stroke afasia motorik melalui transformasional leadership.

Data didapat dari buku dan database : Pubmed, Science Direct dan Google Cendekia dengan menggunakan keyword Augmentative and Alternative Comunication ( $A A C$ ), stroke, afasia dan transformasional leadership.

Pencarian database dibatasi 10 tahun terakhir (2008-2018), dengan tujuan untuk menemukan evidence terbaru.

\section{Hasil \& Pembahasan}

Teori Henderson dalam (Parker, 2001) mendefinisikan keperawatan sebagai upaya membantu individu untuk mendapatkan kebebasan dalam beraktivitas melalui komunikasi dengan orang lain untuk mengekspresikan emosi, kebutuhan rasa takut dan mengemukakan pendapat.

Teori Henderson memberikan petunjuk bahwa salah satu metode yang diberikan pada pasien yang mengalami afasia untuk mencapai kemandirian adalah dengan meningkatkan latihan komunikasi dengan menggunakan alat bantu sebagai media komunikasi alternative dimana seorang perawat menjadi role model memberikan arahan dan pelatihan dalam tindakan keperawatan augmentative and alternative comunication (Parker, 2001).

Faktor yang mempengaruhi latihan komunikasi pasien stroke afasia motorik salah satunya adalah motivasi, semakin tinggi motivasi seseorang dalam melakukan pelatihan dan pembelajaran maka semakin terampil dalam hal komunikasi (Corallo et al., 2017).

Sesuai dengan penerapan gaya kepemimpinan transformasional seorang pemimpin mendorong untuk meningkatkkan tindakan augmentative and 
alternative comunication pada pasien stroke afasia motorik dengan cara mengkaji fungsi bicara dan berbahasa, menyesuaikan teknik berkomunikasi dengan kemampuan pasien (Mulyatsih, dalam Rasyid \& Soertidewi, 2007 dalam Amila, 2012).

Peran pemimpin transformasional dalam meningkatkan AAC melalui 4 tahap yaitu Idealized influence, Inspirational motivation, Intellectual stimulation, Individualized consideration (Anwar, dkk (2012) dalam Totononu \& Dwiantoro, n.d.).

Tindakan Augmentative and Alternative Communication (AAC) pada pasien stroke afasia motorik ini dapat diberikan dengan cara inspirational motivation di mana perawat memberi motivasi yang kuat untuk berubah, memberi inspirasi agar dapat merangsang antusiame bawahan terhadap penerapan AAC. Hal ini sependapat dengan penelitian yang dilakukan oleh Pradhanawati (2012) 84,9\% gaya kepemimpinan transformasional berpengaruh terhadap motivasi kerja.

Dalam memotivasi untuk menerapkan AAC pemimpin perlu konsiderasi individu (individualized consideration) yaitu mendengar masukan-masukan untuk mau berubah menerapkan AAC. Pemimpin sebagai mentor yang memiliki Idealized influence atau kharisma membuat para pengikutnya mau berlatih AAC, dengan cara mengkaji fungsi bicara dan berbahasa, menyesuaikan teknik berkomunikasi dengan kemampuan pasien afasia motorik. Selain itu pemimpin dapat melakukan perubahan dengan cara stimulasi intelektual (intellectual stimulation) terhadap permasalahan penerapan AAC dengan cara mendorong bawahan agar melihat persoalan afasia motorik dapat diminimalisir dengan AAC, atau dengan kata lain membuat mereka lebih sadar mengenai pentingnya penerapan $A A C$ dalam pemulihan afasia pasien stroke.

Keberhasilan terapi AAC ditentukan oleh latihan yang sering. Menurut (Bakhiet, et.al, dalam Amila, 2012) latihan secara intensif dapat meningkatkan neuralplasticity, reorganisasi peta kortikal dan meningkatkan fungsi motorik.

Dalam rehabilitasi stroke, perawat dapat berperan sebagai caregiver, fasilitator dalam penyembuhan pasien dan manajer perawatan. Peran ini diharapkan mampu meningkatkan komunikasi pasien afasia motorik melalui AAC dengan penggunaan metode media komunikasi yang mudah dipahami tentang sebuah informasi. Latihan komunikasi menggunakan AAC dapat meningkatkan interaksi dengan orang lain dan lingkungan sehingga mempengaruhi kesejahtraan pasien, kemandirian, partisipasi sosial, dan kualitas hidup (Corallo et al., 2017).

Penelitian yang dilakukan oleh Pattiasina (2011) menunjukkan bahwa gaya kepemimpinan memiliki pengaruh positif terhadap kinerja pelayanan. Dalam hal ini perubahan menuju keadaan yang baru atau tingkat/tahap perkembangan baru karena memiliki cukup informasi, memiliki sikap dan kemampuan untuk berubah, memahami masalah yang dihadapi, dan mengetahui bahwa untuk menyelesaikan masalah afasia motorik perlu penerapan AAC.

\section{Kesimpulan}

Kepemimpinan transformasional yang dicirikan dengan pengaruh ideal, motivasi inspirasi, stimulasi intelektual dan pertimbangan individu yang diterapkan oleh pemimpin organisasi berperan besar dalam mencapai keberhasilan terapi AAC.

Gaya kepemimpinan transformasional berpengaruh positif terhadap peningkatan terapi AAC. Hal ini dikarenakan seorang pemimpin memotivasi bawahannya untuk melakukan pendekatan komunikasi dan latihan bimbingan terapi AAC terhadap pasien yang mengalami Afasia motorik.

\section{Bibliografi}

1. Amila. (2012). Pengaruh Pemberian Augmentative and Alternative Communication (AAC) Terhadap Kemampuan Fungsional Komunikasi Dan Depresi Pasien Stroke Dengan Afasia Motorik Di Rsud Garut, Tasikmalaya Dan Banjar. Universitas Indonesia, lib.ui.ac.id/file?file=digital/20298415-T29939-

Pengaruh\%20pemberian.pdf diakses tanggal 20 Agustus 2018

2. Amila, Sitorus, R., \& Herawati, T. (2015). Pengaruh Pemberian Augmentative and Alternative Communication (AAC) Terhadap Kemampuan Funfsional, 18(2), 95-101. jki.ui.ac.id/index.php/jki/article/view/410. Diakses tanggal 20 Agustus 2018

3. Bahr, E. (2008). Light Technology Augmentative 
Communication for Acute Care and Rehab Settings. Topics in Stroke Rehabilitation, 15(4), 384-390. https://doi.org/10.1310/tsr1504-384

4. Beukelman, D. R., Hux, K., Dietz, A., McKelvey, M., \& Weissling, K. (2015). Using Visual Scene Displays as Communication Support Options for People with Chronic, Severe Aphasia: A Summary of AAC Research and Future Research Directions. AAC: Augmentative and Alternative Communication, 31(3), 234-245.

https://doi.org/10.3109/07434618.2015.1052152

5. Corallo, F., Bonanno, L., Buono, V. Lo, Salvo, S. De, Rifici, C., Pollicino, P., Marino, S. (2017). Augmentative and Alternative Communication Effects on Quality of Life in Patients with Locked-in Syndrome and Their Caregivers. Journal of Stroke and Cerebrovascular Diseases, 1-5. https://doi.org/10.1016/j.jstrokecerebrovasdis.2017.06 .026

6. Dwi, G., Haryanto, A., Setyawan, D., Argo, M., \& Kusuma, B. (2014). Pengaruh Terapi AlUEO Terhadap Kemampuan Bicara Pada Pasien Stroke Yang Mengalami Afasia Motorik Di RSUD Tugurejo Semarang. Jurnal IImu Keperawatan Dan Kebidanan (JIKK), 1-11.

7. Nursalam. (2015). Manajemen Keperawatan Aplikasi dalam Praktik Keperawatan Profeional, 1-5. https://ners.unair.ac.id/materikuliah/BUKU-

MANAJEMEN-2011.pdf diakses Tanggal 18 Agustus 2018

8. Parker, M. E. (n.d.). Nursing Theories and Nursing Practice.

docshare03.docshare.tips/files/26827/268274013.pdf diakses Tanggal 28 Agustus 2018

9. Pattiasina, V. (2011). Pengaruh Gaya Kepemimpinan Transformasional Terhadap Kinerja Pelayanan Ddengan Budaya Kerja dan Good Corporate Governance Sebagai Variabel Moderasi.

10. Pinzon. R. T. 2016. Awas Stroke, Betha Grafika, Yogyakarta.

11. Pradhanawati, A. H. S. (2012). Pengaruh Budaya Organisasi dan Gaya Kepemimpinan Transformasional Terhadap Kinerja Karyawan Melalui Disiplin Kerja Pada Karyawan Harian SKT Megawon II PT Djarum Kudus, 1-8. garuda.ristekdikti.go.id/author/view/332786 diakses Tanggal 05 September 2018

12. Totononu, A. E., \& Dwiantoro, L. (n.d.). Sistematik Review: Gaya Kepemimpinan Yang Dapat Meningkatkan Kepuasan Kerja Perawat, 192-202. eprints.undip.ac.id/61163/1/13.pdf diakses Tanggal 05 September 2018

13. Yudiaatmaja, F. (2013). Issn 1412 - 868329. Kepemimpinan : Konsep, Teori Dan Karakternya, (3),
29-38.

https://ejournal.undiksha.ac.id/index.pp/MKFIS/article /viewFile/1681/1469. Diakses Tanggal 25 Agustus 2018 